\title{
Adrenal Incidentaloma: A Cautionary Tale of Three Cases of Adrenocortical Carcinoma Arising from Apparently Benign Incidentalomas
}

\author{
${ }^{1}$ Chris Armstrong, ${ }^{2}$ Janice L Pasieka, ${ }^{3}$ Adrian Harvey \\ ${ }^{1}$ Resident, Department of Surgery and Oncology, Division of General Surgery, University of Calgary, Foothills Hospital \\ Alberta Health Services, Alberta T2N 2T9, Canada \\ ${ }^{2}$ Clinical Professor, Department of Surgery and Oncology, Division of General Surgery, University of Calgary \\ Foothills Hospital, Alberta Health Services, Alberta T2N 2T9, Canada \\ ${ }^{3}$ Clinical Assistant Professor, Department of Surgery and Oncology, Division of General Surgery \\ University of Calgary, Foothills Hospital, Alberta Health Services, Alberta T2N 2T9, Canada
}

Correspondence: Janice L Pasieka, Clinical Professor, Department of Surgery and Oncology, Division of General Surgery University of Calgary, Foothills Hospital, Alberta Health Services, 1403-29th Street NW Calgary, Alberta T2N 2T9, Canada Phone: 403-944-2491, Fax: 403-283-4130, e-mail: janice.pasieka@albertahealthservices.ca

\section{ABSTRACT}

Unexpected incidental findings on cross-sectional imaging are becoming more commonplace in today's medical practice. These are likely due to ongoing improvements in the resolution of cross-sectional imaging and our increasing use of these tests combined with an aging population. In the case of the adrenal incidentalomas the majority of these represent benign nonfunctional adenomas and these are believed to have no malignant potential. On the contrary adrenocortical carcinoma (ACC) is an uncommon malignancy that carries a high mortality. Current biochemical and radiological follow-up investigations are expensive and are of limited benefit in the majority of cases of adrenal incidentalomas. This has created a dilemma for the proper diagnostic, clinical and radiologic follow-up as well as the triggers for surgical intervention. We present a series of three patients presenting with ACC that retrospectively arose from a small incidentally found adrenal lesion. Three patients were identified with ACC arising from an apparently benign adrenal incidentaloma. The average size of the original lesion was $1.6 \mathrm{~cm}$ whereas the average size of their adrenal tumor was $9.3 \mathrm{~cm}$ when they presented with ACC. Two of the three cases were found to develop functional tumors at the time of the diagnosis of ACC. Two of the three cases underwent surgical resection. The third patient was found to have metastatic disease at presentation and declined surgical intervention. We agree that current follow-up guidelines result in an increasing burden on our healthcare system; with expensive biochemical testing and imaging for what in most cases will prove to be a benign adenoma, these three cases have influenced our current strategies for follow-up. At the present time, we continue to follow the AAES/AACE guidelines. The development of improved methods of biochemical, radiologic and tissue diagnosis may help to improve our ability to recognize an ACC in this population at an earlier and potentially curable stage.

Keywords: Adrenal incidentaloma, Adrenocortical carcinoma, Diagnosis, Treatment, Follow-up.

\section{INTRODUCTION}

With ongoing improvements in the resolution of current radiologic modalities, adrenal incidentalomas are being diagnosed with increasing frequency. Current studies suggest incidental lesions of the adrenal gland are discovered in 5 to $10 \%$ of abdominal CT scans. ${ }^{1-5}$ Incidental masses of the adrenal gland also appear to be more frequent in older populations. ${ }^{6,7}$ With both an aging population and the increasing use of cross-sectional imaging, adrenal incidentalomas represent a significant health issue. The practice of long-term radiologic and clinical follow-up is too expensive and of questionable benefit in the majority of cases. ${ }^{8}$ While the majority of these lesions are benign and nonfunctional it has been reported that 16 to $47 \%$ develop endocrine functionality ${ }^{6,9}$ and 4.7 to $10 \%$ of cases may ultimately prove to be malignant tumors of the adrenal gland. ${ }^{10}$ This has created a dilemma for the proper diagnostic, clinical and radiologic followup as well as the triggers for surgical intervention.

Histopathologically, the majority of adrenal incidentalomas are benign nonfunctional adenomas and believed to have essentially no malignant potential. ${ }^{1}$ On the contrary, adrenocortical carcinoma (ACC) is an uncommon malignancy that carries a high mortality. The majority of patients with these tumors present late with advanced disease. As a result, the overall 5-year survival for ACC is poor. ${ }^{11,12}$ The discovery of an ACC at the time of adrenalectomy for incidentaloma has been associated with a much more favorable prognosis than those cancers that are discovered clinically. ${ }^{11}$ Since complete surgical resection offers the only chance for cure, intervening early, on smaller tumors increases the likelihood of a potentially curative $\mathrm{R} 0$ resection. 
The task of appropriately investigating and managing patients with adrenal incidentalomas in an era of increasing healthcare costs represents a considerable challenge. In the instance of ACC constant surveillance may permit intervention at an early stage and favorably affect patient survival. However, the correct radiologic follow-up that appropriately balances quality of care and patient outcome with costs of intervention, radiation exposure and the risk of unnecessary surgery continues to be debated. ${ }^{7,8,13} \mathrm{We}$ present here a series of three patients presenting with ACC that retrospectively arose from a small incidentally found adrenal lesion as well as a review of the current literature (Table 1).

\section{CASE REPORTS}

\section{Case 1}

A 33-year-old woman underwent enhanced CT scan of the abdomen in a work-up for vague abdominal pain. She was not found to have any abnormalities on this examination apart from a small ( $9 \mathrm{~mm})$ hypoattenuating tumor to her right adrenal gland, the imaging characteristics of which appeared benign. This was further investigated with an MRI, which also confirmed a small $1.4 \mathrm{~cm}$ benign appearing lesion of the right adrenal gland. With the remaining investigations all negative, she was given the diagnosis of irritable bowel syndrome. Her pain, however, persisted over the next 6 months which prompted a visit to a local emergency department and repeat imaging. At this time, the CT scan revealed a $9 \mathrm{~cm}$ enhancing mass that appeared to invade the inferior vena cava (IVC) (Figs 1A and B). Her 24-hour urinary metanephrines, 24-hour urinary cortisol, DHEAS and aldosterone/renin ratio were all normal. A subsequent MRI demonstrated a $3.7 \mathrm{~cm}$ tumor thrombus extending into the IVC to just below the take off of the middle hepatic and right hepatic veins. The patient was noted to have a lesion in the liver consistent with a hemangioma. There was no evidence for metastatic disease apart from a $6 \mathrm{~mm}$ lesion in the right lung which was shown to be negative on FDG-PET scan.

The patient underwent surgical resection by a surgical team, including members from endocrine, hepatobiliary and vascular surgery. Intraoperatively, the tumor was noted to locally invade the diaphragm and the tumor thrombus was noted to extend above the diaphragm approaching the right atrium. The tumor was taken en bloc with the right kidney as well as a piece of the right hemidiaphragm and a partial segment (1/3 circumference) of the adjacent IVC. The tumor thrombus was extracted from below the diaphragm.

Final pathology revealed a high-grade T4 ACC with evidence for extraadrenal extension into the right kidney to a depth of $3 \mathrm{~mm}$. There was no evidence of lymph node metastasis or perineural invasion. The tumor was noted to have a high mitotic index (100 mitoses/50 HPF with atypical mitosis) and evidence for extensive necrosis. There was evidence for venous extension into the vena cava with a microscopically positive margin on the IVC. The patient's postoperative course was uneventful. Given her positive margin she was placed on mitotane postoperatively. She has subsequently recurred at the tumor bed within 6 months following her surgery. At the present time consideration for additional chemotherapeutic options is being discussed with the patient.

\section{Case 2}

A 48-year-old female was being investigated for recurrent hyperparathyroidism after undergoing a four gland parathyroid exploration at the age of 31 years. Selective venous sampling for PTH was required since anatomical and functional imaging failed to localize any parathyroid disease in her neck. While undergoing fluoroscopy during her selective venous sampling she was noted to have a suspicious appearing mass in the upper lobe of her right lung. A CT scan of her chest and abdomen was done the following week supported the diagnosis of pneumonia in the right upper lobe of the lung. However, a $7 \mathrm{~cm}$ inhomogeneous mass in her left adrenal gland was noted (Figs 2A and B). Retrospective review of her previous imaging demonstrated an unreported small less than $1 \mathrm{~cm}$ homogeneous lesion of her left adrenal gland that was present on a CT scan done 11 months prior when she presented with a history consistent with renal colic. Although, she did not have overt manifestations of Cushing's syndrome, biochemical assessment demonstrated an elevated 24-hour urinary cortisol (439 $\mu \mathrm{mol})$. The rest of her biochemical screening, including 24-hour urinary metanephrines and D-HEAS, were normal.

She underwent an open left adrenalectomy with en bloc nephrectomy. Pathologic assessment revealed an $11 \mathrm{~cm} \mathrm{ACC.}$ She had clear surgical margins without evidence of extracapsular extension but was noted to have nuclear atypia, high mitotic range (13 mitoses/hpf) and evidence of venous invasion. She was placed on adjuvant mitotane therapy postoperatively. During follow-up she developed disease progression after presenting with recurrent clinical and biochemical Cushing's syndrome and was subsequently found to have metastatic disease in both her spine and lungs. She was placed on a palliative chemotherapy regimen of etoposide, doxorubicin, cisplatin and mitotane. She died 3 months later.

Table 1: Series of three patients found to have ACC arising from an incidentally found benign appearing lesion of the adrenal gland

\begin{tabular}{cccccccc}
\hline Case & Patient age & Sex & $\begin{array}{c}\text { Initial } \\
\text { incidentaloma } \\
\text { size }(\mathrm{cm})\end{array}$ & $\begin{array}{c}\text { Functional } \\
\text { screen at time } \\
\text { of initial imaging }\end{array}$ & $\begin{array}{c}\text { Interval } \\
\text { (months) }\end{array}$ & $\begin{array}{c}\text { ACC size at } \\
\text { presentation } \\
(\mathrm{cm})\end{array}$ & Functional \\
\hline 1 & 33 years & $\mathrm{F}$ & 0.9 & No & 6 & 9 & No \\
2 & 48 years & $\mathrm{F}$ & 1 & Yes & 11 & 7 & Cortisol \\
3 & 78 years & $\mathrm{F}$ & 2.8 & No & 70 & 12 & Cortisol/androgen \\
\hline
\end{tabular}




\section{Case 3}

A 77-year-old female presented with a 6-month history of progressive hirsutism and florid manifestations Cushing's syndrome. Her chief complaint at presentation was worsening proximal muscle weakness over the preceding 6 months. She was noted to have markedly elevated 24-urine cortisol (681 $\mathrm{nmol})$ and a suppressed ACTH (1.8 pmol/L). Furthermore, she had an elevated free androgen index of $15.1 \mathrm{nmol} / 1$ and an elevated serum testosterone of $5.9 \mathrm{nmol} / \mathrm{l}$. CT scan and MRI were done at this time demonstrated a large heterogeneous appearing mass measuring $12 \mathrm{~cm}$ in diameter with invasion into the liver and evidence of extension into the IVC (Figs 3A and B). CT of her chest demonstrated several nodules in her lungs bilaterally as well as mediastinal lymphadenopathy. These were found to be metabolically active on FDG-PET imaging consistent with metastatic disease. Retrospectively this patient was known to have an incidental lesion of the right adrenal gland on a CT scan done 6 years prior while undergoing

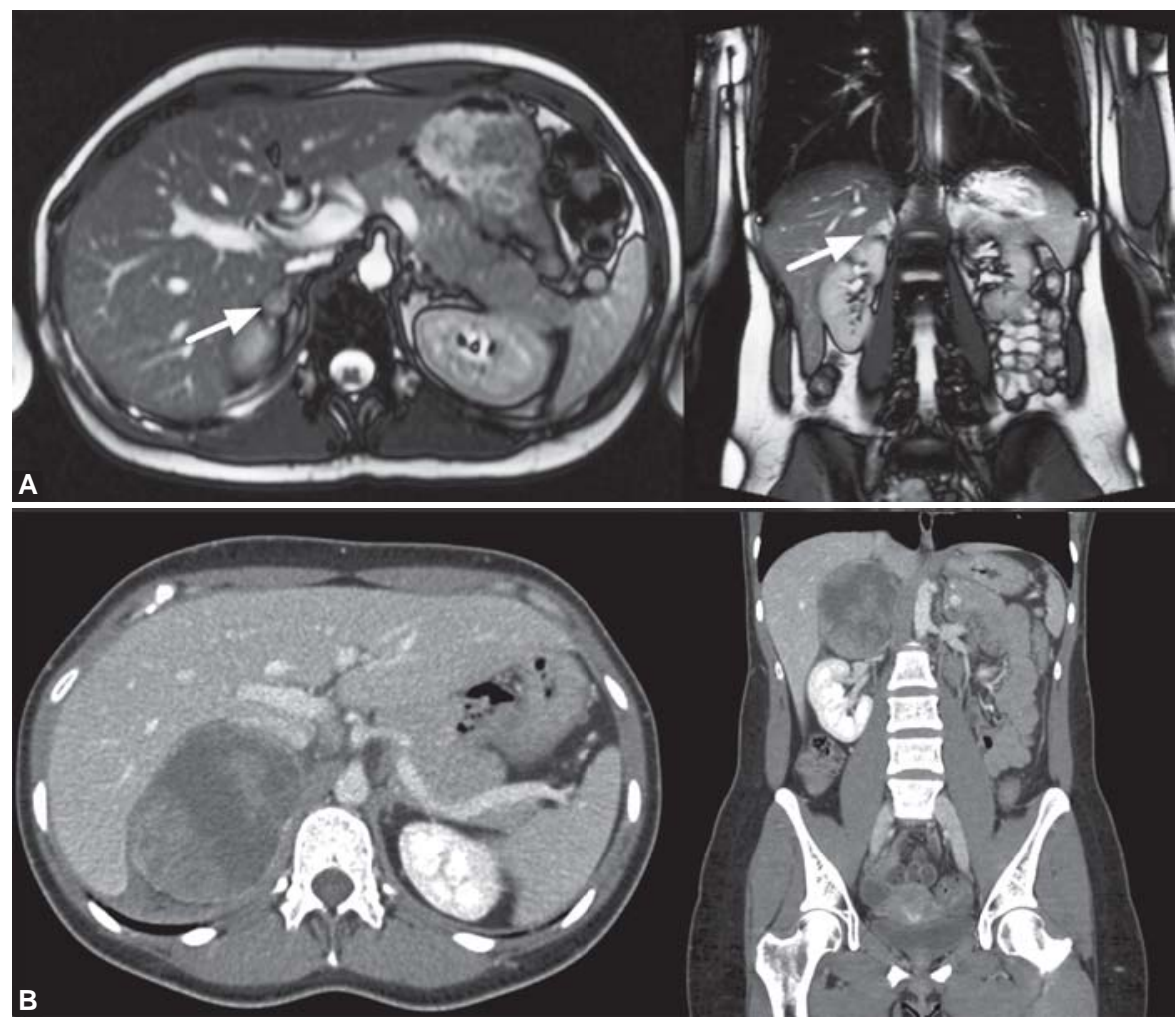

Figs $1 \mathrm{~A}$ and B: Imaging findings of patient no. 1 at the time of her initial presentation with an incidentally found lesion of her right adrenal gland which was later noted to develop into an ACC. (A) T2- weighted MRI of an incidental lesion $(1 \mathrm{~cm})$ of the right adrenal gland, (B) enhanced CT tomogram demonstrating a large heterogeneous $9 \mathrm{~cm}$ mass of the right adrenal gland 9 months later. The tumor was shown to have tumor thrombus extending into the IVC. Final pathology demonstrated this to be a high grade ACC

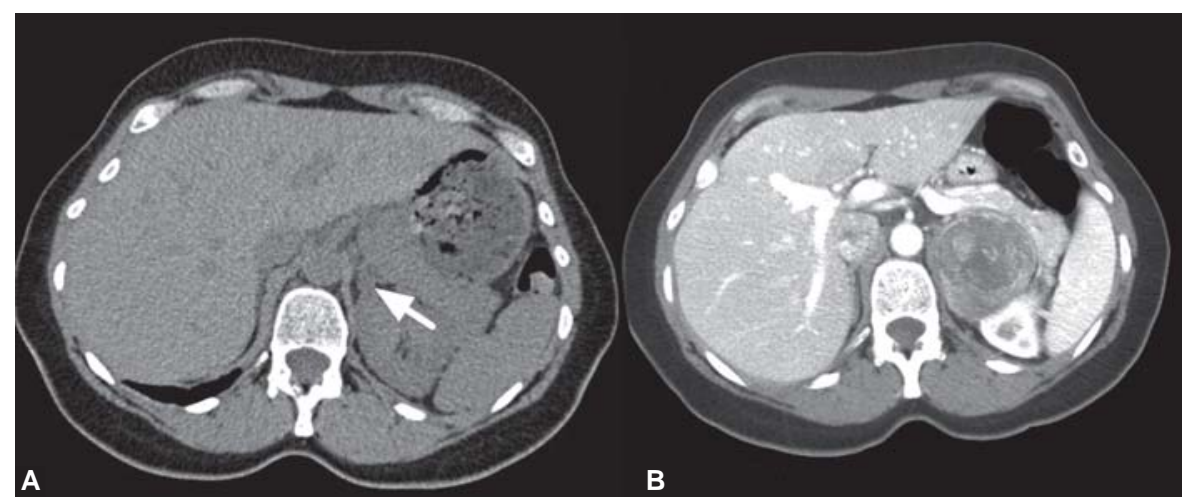

Figs 2A and B: Imaging findings of patient no. 2. A 48-year-old female with a history of recurrent hyperparathyroidism was found to have an inhomogeneous mass arising from her left adrenal gland during work-up for an apparent chest mass seen on fluoroscopy at the time of her selective venous sampling. (A) An nonenhanced CT scan done for work-up of renal colic demonstrating a benign appearing incidental lesion of the left adrenal gland arrow. (B) An enhanced CT scan done 11 months later demonstrating a large mass arising from the left adrenal gland, this was later demonstrated to be ACC 
investigations for complicated pyelonephritis. At that time, the CT scan revealed a $2.8 \mathrm{~cm}$ hypoattenuating, well-circumscribed homogenous lesion of her right adrenal gland. Biochemical investigations were normal and a follow-up CT scan 6 months later demonstrated a decrease in the size of the lesion $(2.5 \mathrm{~cm})$. The patient was told no further investigations were required given the obvious nonfunctioning, benign nature of this incidentally found lesion. Given the patient's age, her medical comorbidities and evidence of extensive metastatic disease at this time, the decision was made to proceed with medical palliation.

\section{DISCUSSION}

Three factors have contributed to a steady increase in the prevalence of incidentally discovered lesions of the adrenal gland: (1) Our increasing reliance on diagnostic imaging; (2) the increasing resolving power of these investigations; and (3) a progressively aging population..$^{3,14-17}$ Recent series cite the prevalence of incidental lesions of the adrenal gland at $5 \%$ of abdominal CT scans done for other reasons. ${ }^{14}$ This is approximately double the rate at which these lesions were detected in older series. ${ }^{2,4,18,19}$ Adrenal lesions also appear to be more common in older patients and may be as frequent as $7 \%$ in patients $>70$ years of age. ${ }^{17}$ Autopsy series cite the rate of incidental lesions of the adrenal gland as high as $8.7 \% .{ }^{6}$ More recent radiologic series are approaching this figure and have identified that these lesions are likely underreported. ${ }^{14,21}$

Currently, decision-making algorithms regarding proper management for incidentalomas are based on imaging characteristics and tests for biochemical functionality. The American Association of Endocrine Surgery (AAES) and American Association of Clinical Endocrinology (AACE) have recently published guidelines on the work-up and evaluation of adrenal incidentalomas ${ }^{13}$ (Table 2). These guidelines have been shown to be reasonably accurate in appropriately assigning a diagnosis. ${ }^{20}$ These guidelines suggest that all incidentally found adrenal lesions should be screened for biochemical functionality at the time of diagnosis and then annually for up to 5 years. ${ }^{13}$ This most commonly includes a low-dose dexamethasone suppression test and urinary or plasma metanephrines. Determination of the aldosterone/renin ratio can be done in hypertensive patients, while screening for sex hormone secretion is reserved for patients with obvious clinical signs. Lesion size and attenuation values are the two most important characteristics in determining the likelihood that a lesion is benign. The risk of malignancy in lesions less than $4 \mathrm{~cm}$ is extremely low $(<4 \%)$, whereas the risk of malignancy increases dramatically to approximately $25 \%$ with lesions greater than $6 \mathrm{~cm}$. Small lesions $(<4 \mathrm{~cm})$ with attenuation values less than $10 \mathrm{HU}$ likely represent benign adrenocortical adenomas. ${ }^{22}$ It is currently recommended that tumors greater than $4 \mathrm{~cm}$ in size or those showing growth over follow-up should be considered for resection. ${ }^{9,22}$ Current recommendations suggest that those lesions that do not fill the criteria for surgical resection should be followed radiographically with repeat cross- sectional imaging at 3 to 6 months and 1 to 2 years. ${ }^{13}$ Further, advances in imaging techniques MRI phase-shift characteristics and CT washout analysis have allowed for better characterization of equivocal cases. ${ }^{5,23}$ In a recent radiologic series imaging characterization provided a specific diagnosis in $87 \%$ of all adrenal masses and the diagnosis could be made at the initial CT in $62 \%$ of cases. $^{24}$

In an era that has seen the provision of high-quality medical care become increasingly more expensive the routine practice of long-term radiologic and endocrine biochemical follow-up has been called into question. ${ }^{8}$ In one study, biochemical screening of even $1 \mathrm{~cm}$ adrenal incidentalomas appears to be more cost-effective than clinical follow-up. ${ }^{25}$ For this reason routine radiologic and biochemical follow-up of incidentalomas is what most published guidelines currently recommend ${ }^{26}$ (Table 2). However, in this recent review of adrenal incidentalomas, Cawood et al called into question the value of the current guidelines. ${ }^{8}$ The authors felt that guidelines relied heavily on surgical and pathologic series that because of their

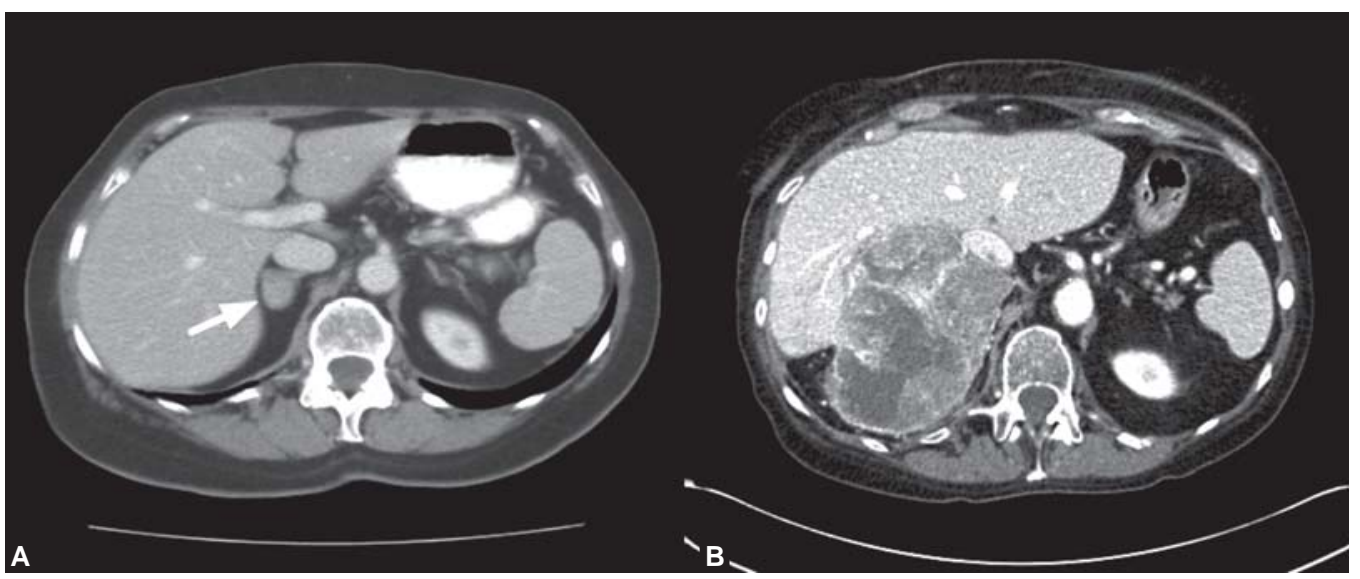

Figs $3 A$ and B: Imaging findings of patient no. 3 who was found to have ACC after presenting with clinically progressive weakness, hirsutism and features of Cushing's syndrome. A CT scan done 6 years prior demonstrated a benign appearing lesion of the right adrenal gland. (A) Enhanced CT scan done at 6 months follow-up of incidentally found lesion of the right adrenal gland, $(B)$ an enhanced CT scan done 6 years later when patient presented with Cushing's syndrome. At this time, a heterogeneous mass arising from the right adrenal gland was noted along with evidence of metastatic disease in the chest 


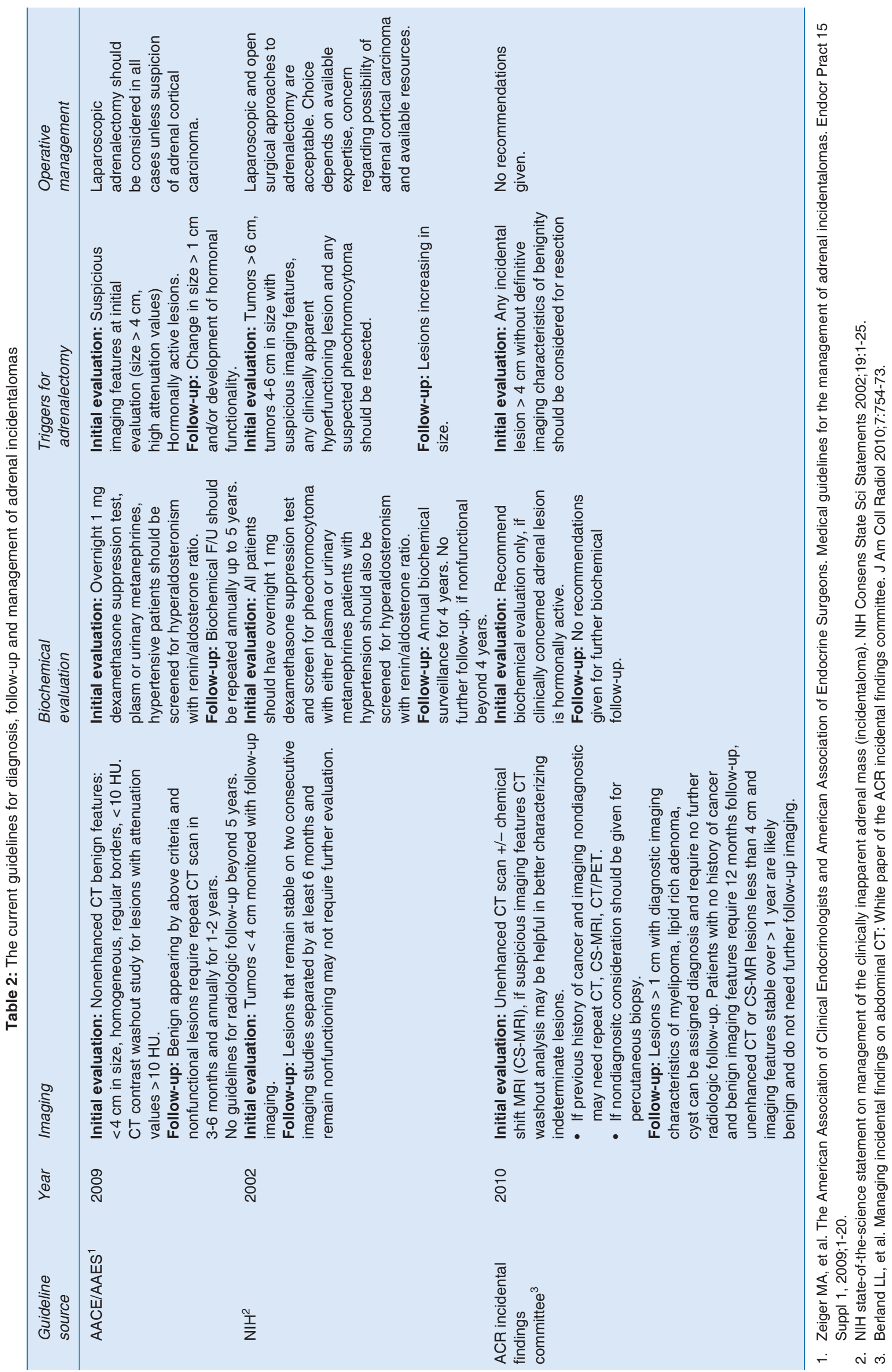


inherent bias tend to overestimate the risk of malignancy. When a more broad range of patients was considered the authors noted that most cases of adrenal incidentalomas represent benign lesions and the risk of ACC in small benign appearing lesions is extremely low. They went on to conclude that the chance of detecting an ACC during CT follow-up of benign appearing incidentalomas less than $4 \mathrm{~cm}$ in size was similar to the chance of inducing fatal cancer from added radiation exposure. ${ }^{8}$ Most prospective studies are heterogeneous with respect to the length of follow-up and many lack sufficient numbers to capture the occurrence of an ACC amongst patients followed for a 'true' adrenal incidentaloma. Surgical and oncological series introduce bias and as such likely overestimate the true prevalence of malignancy in adrenal incidentalomas. Thus, the natural history of ACCs occurring in incidentally discovered adrenal lesions is uncertain. ${ }^{11}$ Most radiologic series are limited by their lack of clinical and histopathologic confirmation of diagnosis ${ }^{1}$ so it remains unclear whether those patients developing ACC represent development of malignant phenotype during followup or whether a malignancy was present at the outset of investigation.

Pathologic diagnosis of ACC remains difficult and is typically made following surgical resection. There is currently little role for image-guided biopsy of adrenal incidentaloma. ${ }^{27}$ Adrenal biopsy is often unable to differentiate benign from malignant adrenal cortical lesions and often has low yield for obtaining sufficient tissue to alter therapy. This diagnostic modality is typically reserved for patients with a previous history of cancer to rule out metastatic disease or when adrenal lymphoma is suspected. ${ }^{28}$ Recent reports highlight the potential of various biologic markers in differentiating benign adrenal lesions from malignancy. IGF-2 is highly expressed in ACCs and its corresponding MiRNA (mi-483-5p) is also highly expressed in ACC specimens. ${ }^{29}$ Furthermore, IGF-2 and Mi-483-5p may play a role in carcinogenesis and represents a potential therapeutic target. Differential MiRNA expression has also been demonstrated in other cancers. ${ }^{30,31}$ RNA transcriptome work has also been demonstrated to help delineate ACCs that are particularly aggressive. ${ }^{32,33}$ These techniques may represent a means to better characterize indeterminate incidentalomas assist in prognostication of resected tumors and may be helpful in accurately staging patients with ACC.

An incidentally discovered adrenal lesion raises the possibility of a primary adrenal cancer. Although ACC is a rare malignancy with a prevalence of 1 to 2 cases per million, it portends a poor prognosis and is responsible for $\sim 0.2 \%$ of all cancer deaths per year. ${ }^{11,31,34}$ The majority of cases are diagnosed late when patients present with symptoms related to large mass that is subsequently characterized by cross-sectional imaging. ${ }^{39}$ For these reasons, numerous guidelines for

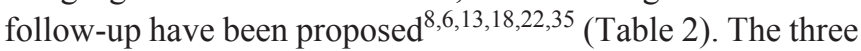
cases reported here illustrate the challenges of such guidelines. All three cases had benign appearing lesions on CT scanning. In cases 1 and 2 the initial adrenal lesions were so 'innocent' appearing that no biochemical workup or follow-up of the lesion was recommended. Serendipity resulted in anatomical imaging within that year that demonstrated the aggressive and rapid growth of the initial lesions. Case 3 followed guidelines that deemed the lesion to be nonfunctioning and on repeat imaging decreasing in size. Clearly this ACC progressed over the course of the following 6 years. In all three cases one cannot help but wonder if surgical intervention done on the initial lesion, would have prevented the development of metastatic ACC. Yet, the size of the lesions in cases 1 and 2 would hardly warrant surgical intervention based on size criteria alone.

\section{CONCLUSION}

The diagnosis work-up and management of patients presenting with an adrenal incidentaloma continues to represent a challenging scenario. The series of patients we present here also highlights the inherent heterogeneity of this group of patients. Although incidentally identified lesions of the adrenal are most commonly benign, they have the potential to represent a rare malignancy associated with a high mortality. Current screening tests are limited by the trade-off between being sensitive enough to detect the rare occurrence of lethal malignancy with the potential morbidity of recommending unneeded surgery in patients with benign disease. Added to that is the risk of cancer development with increased radiation exposure on follow-up imaging. In this day and age of the need to control health care cost and limit unnecessary radiation exposure, some authors have proposed that no further testing of small nonfunctioning incidentalomas is required. ${ }^{8}$ Although we agree that current follow-up guidelines result in an increasing burden on our healthcare system; with expensive biochemical testing and imaging for what in most cases will prove to be a benign adenoma, these three cases have influenced our current strategies for follow-up. At the present time we continue to follow the AAES/AACE guidelines. The development of improved methods of biochemical, radiologic and tissue diagnosis may help improve our ability to recognize an ACC in this patient population at an earlier potentially curable stage.

\section{REFERENCES}

1. Song JH, Chaudhry FS, Mayo-Smith WW. The incidental adrenal mass on CT: Prevalence of adrenal disease in 1,049 consecutive adrenal masses in patients with no known malignancy. AJR Am J Roentgenol 2008;190(5):1163-68.

2. Caplan RH, Strutt PJ, Wickus GG. Subclinical hormone secretion by incidentally discovered adrenal masses. Arch Surg 1994;129(3):291-96.

3. Bovio S, Cataldi A, Reimondo G, Sperone P, Novello S, Berruti A, et al. Prevalence of adrenal incidentaloma in a contemporary computerized tomography series. J Endocrinol Invest 2006;29(4):298-302.

4. Herrera MF, Grant CS, van Heerden JA, Sheedy PF, Ilstrup DM. Incidentally discovered adrenal tumors: An institutional perspective. Surgery 1991;110(6):1014-21.

5. Blake MA, Holalkere N, Boland GW. Imaging techniques for adrenal lesion characterization. Radiol Clin North Am 2008;46(1):65-78, vi.

6. Barzon L, Sonino N, Fallo F, Palu G, Boscaro M. Prevalence and natural history of adrenal incidentalomas. Eur J Endocrinol 2003;149(4):273-85 
7. Mansmann G, Lau J, Balk E, Rothberg M, Miyachi Y, Bornstein SR. The clinically inapparent adrenal mass: Update in diagnosis and management. Endocr Rev 2004;25(2):309-40.

8. Cawood TJ, Hunt PJ, O'Shea D, Cole D, Soule S. Recommended evaluation of adrenal incidentalomas is costly, has high falsepositive rates and confers a risk of fatal cancer that is similar to the risk of the adrenal lesion becoming malignant; time for a rethink? Eur J Endocrinol 2009;161(4):513-27.

9. NIH state-of-the-science statement on management of the clinically inapparent adrenal mass ("incidentaloma"). NIH Consens State Sci Statements 2002;19(2):1-25.

10. O’Neill CJ, Spence A, Logan B, Suliburk JW, Soon PS, Learoyd DL, et al. Adrenal incidentalomas: Risk of adrenocortical carcinoma and clinical outcomes. J Surg Oncol Oct 1, 2010;102(5):450-53.

11. Tauchmanovà L, Colao A, Marzano LA, Sparano L, Camera L, Rossi A, et al. Adrenocortical carcinomas: Twelve-year prospective experience. World J Surg Sep 1, 2004;28(9): 896-903.

12. Icard P, Goudet P, Charpenay C, Andreassian B, Carnaille B, Chapuis Y, et al. Adrenocortical carcinomas: Surgical trends and results of a 253-patient series from the French Association of Endocrine Surgeons study group. World J Surg July 2001; 25(7):891-97.

13. Zeiger MA, Thompson GB, Duh Q, et al. American Association of clinical endocrinologists and American association of endocrine surgeons medical guidelines for the management of adrenal incidentaloma. Endocrine Practice 2009;15(Suppl 1) $1-20$.

14. Hammarstedt L, Muth A, Wängberg B, Björneld L, Sigurjónsdóttir HA, Götherström G, et al. Adrenal lesion frequency: A prospective, cross-sectional CT study in a defined region, including systematic re-evaluation. Acta Radiol 2010;51(10):1149-56.

15. Young WF. Clinical practice. The incidentally discovered adrenal mass. N Engl J Med 2007;356(6):601-10.

16. Grumbach MM, Biller BMK, Braunstein GD, Campbell KK, Carney JA, Godley PA, et al. Management of the clinically inapparent adrenal mass ("incidentaloma"). Ann Intern Med 2003;138(5):424-29.

17. Kloos RT, Gross MD, Francis IR, Korobkin M, Shapiro B. Incidentally discovered adrenal masses. Endocr Rev 1995;16(4):460-84.

18. Gajraj H, Young AE. Adrenal incidentaloma. Br J Surg 1993;80(4):422-26.

19. O'Leary TJ, Ooi TC. The adrenal incidentaloma. Can J Surg 1986;29(1):6-8.

20. Grogan RH, et al. Adrenal incidentaloma: Does an adequate workup rule out surprises? Surgery 2010;148(2):392-97.
21. Song JH, Mayo-Smith W. Incidentally discovered adrenal mass. Radiol Clin North Am 2011;49(2):361-68.

22. Singh PK, Buch HN. Adrenal incidentaloma: Evaluation and management. J Clin Pathol 2008;61(11):1168-73.

23. Sahdev A, Willatt J, Francis IR, Reznek RH. The indeterminate adrenal lesion. Cancer Imaging 2010;10:102-13.

24. Song JH, Chaudhry FS, Mayo-Smith WW. The incidental indeterminate adrenal mass on $\mathrm{CT}(>10 \mathrm{H})$ in patients without cancer: Is further imaging necessary? Follow-up of 321 consecutive indeterminate adrenal masses. AJR Am J Roentgenol 2007;189(5):1119-23.

25. Kievit J. Diagnosis and treatment of adrenal incidentaloma a cost-effectiveness analysis. Endocrinol Metab Clin North Am 2000;29(1):69-90.

26. Wandoloski M, Bussey KJ, Demeure MJ. Adrenocortical Cancer. Surgical Clinics of NA 2009;89(5):1255-67.

27. Quayle FJ, Spitler JA, Pierce RA, Lairmore TC, Moley JF, Brunt LM. Needle biopsy of incidentally discovered adrenal masses is rarely informative and potentially hazardous. Surgery 2007;142(4):497-502; discussion 502-04.

28. Mazzaglia PJ, Monchik JM. Limited value of adrenal biopsy in the evaluation of adrenal neoplasm: A decade of experience. Arch Surg 2009;144(5):465-70.

29. Patterson EE, Holloway AK, Weng J, Fojo T, Kebebew E. Micro RNA profiling of adrenocortical tumors reveals miR-483 as a marker of malignancy. Cancer 2010;117(8):1630-39.

30. Xu T, Zhu Y, Xiong Y, Ge YY, Yun JP, Zhuang SM. Micro RNA-195 suppresses tumorigenicity and regulates G1/S transition of human hepatocellular carcinoma cells. Hepatology 2009;50(1):113-21.

31. Liu L, Chen L, Xu Y, Li R, Du X. Micro RNA-195 promotes apoptosis and suppresses tumorigenicity of human colorectal cancer cells. Biochem Biophys Res Commun 2010;400(2): 236-40.

32. Ragazzon B, Libe R, Gaujoux S, Assie G, Fratticci A, Launay $\mathrm{P}$, et al. Transcriptome analysis reveals that $\mathrm{p} 53$ and $\{$ beta\}-catenin alterations occur in a group of aggressive adrenocortical cancers. Cancer Res 2010;70(21):8276-81.

33. Giordano TJ, Kuick R, Else T, Gauger PG, Vinco M, Bauersfeld J, et al. Molecular classification and prognostication of adrenocortical tumors by transcriptome profiling. Clin Cancer Res 2009;15(2):668-76.

34. Libè R, Fratticci A, Bertherat J. Adrenocortical cancer: Pathophysiology and clinical management. Endocr Relat Cancer 2007;14(1):13-28.

35. Berland LL, Silverman SG, Gore RM, Mayo-Smith WW, Megibow AJ, Yee J, et al. Managing incidental findings on abdominal CT: White paper of the ACR incidental findings committee. J Am Coll Radiol 2010;7(10):754-73. 